\title{
MAGNETIC INDUCTION: A SYSTEM FOR WIRELESS DOWNHOLE COMMUNICATION IN CASED HOLES
}

\author{
P. W. Rodgers
}

May 25, 1973

Prepared for U.S. Atomic Energy Commission under contract No.W-7405-Eng-48

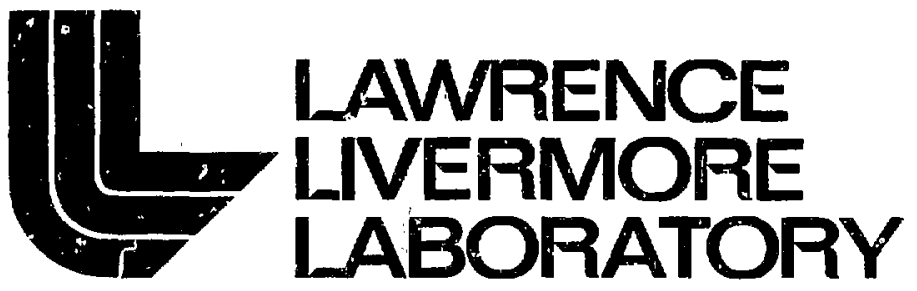

University of California/Livermore

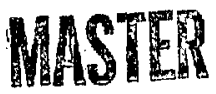


NOTICE

"This report was prepared as an account of work sponsored b. the Ualed States Government. Neither the United States nor the United Statcs Atomic Energy Commission, nor Jny of thei enoployees, nor any cf their contractors, subcontractors, or their employees, makes any waranty, express or implied, or assumes eny legal liability ar responsibility for the accuracy, completeness or uscfulness of any information, apparatus, product or process disclosed, or represents that its use would not infringe priviciyowned rights."

Printed in the United States of America. Available from

National Technical Information Service

U.S. Department of Commerce 5285 Port Royal Road

Springfield, Virginia 22151

Price: Printed Copy \$_*; Microfiche \$0.95

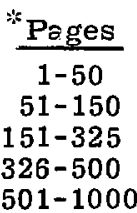

NTIS

Selling Price

$\$ 4.00$

$\$ 5.45$

$\$ 7.60$

$\$ 10.60$

501-1000

$\$ 13.60$ 
TID-4500, UC-38

Engineering and Equipment

\title{
近 \\ LAWRENCE LMEFMOFE LABORATOAY \\ unversity of Cestomia/ Lhermora, Celformia 94550
}

UCRL-51396

\section{MAGNETIC INDUCTION: A SYSTEM FOR WIRELESS DOWNHOLE COMMUNICATION IN CASED HOLES}

\author{
P. W. Rodgers
}

MS. date: May 25, 1973

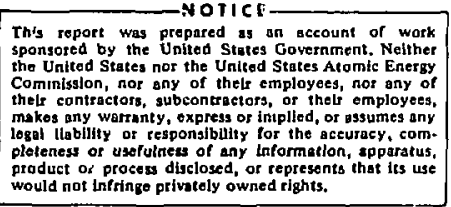




\section{Contents}

Abstract

Litroduction

Magnetic Induction System

Electrical Parameters of Half-Space, Wave Numioer, and Skin Depth . . 3

Magnetic Field

Field Exterior to Casing

Field Interior to Casing

Voltage Induced in Receiving Coil

Optimum Transmitting Frequency

Transient Response

Transmitter Coil

Noise Considerations

Field Experiment

Summary and Conclusions

Acknowledgments

Appendix: Plane Wave Propagation in Good Conductors ․ . . . . 15

Rerarences 


\title{
MAGNETIC INDUCTION: A SYSTEM FOR WIRELESS DOWNHOLE COMMUNICATION IN CASED HOLES
}

\begin{abstract}
A method for wireless downhole communication in a cased hole is described. The system consist 6 of a large horizontal surface loop driven at a low frequency, and a vertical many-turn downhole receiving coil. The downhole coil senses the low frequency induction field produced

by the surface loop. The attenuation due to the conducting rocks and the attenuation through the steel well casing is accounted for theoretically and measured experimentally. A field experiment is described which verifies the theory and practicality of the method.
\end{abstract}

\section{Introduction}

The sequeritial detonation of a series of nuclear explosives in the same drill hole requires some type of alternate cableless communication for command and control because of the possibility that the primary cable link may be destroyed by the initial detonation.

Communication by both seismic and electromagnetic (EM) propagation is possible. This report describes an EM method selected because of the likelihood of a large but unspecified seismic background noise following the initial detonation that might interfere with seismic communication. Although EN waves attenuate rapidly in propagating through the rock and through the metal casing material, the EM noise background appears to be relatively much smaller than and more predictable than the seismic background noise.

The EM method employed-magnetic induction - is borrowed from the geophysical method known as induction sounding. ${ }^{1}$ This geophysical technique is used to determine conductivities deep within the Earth's crust. A large horizontal loop is driven at very low frequencies; the fields penetrate many kilometers so that the coil impedance reflects the conductivities at depth.

\section{Magnetic Induction System}

The configuration for magnetic induction communication is shown in Fig. 1.
A large diameter single-turn coil placed on the surface serves as the transmitter; 


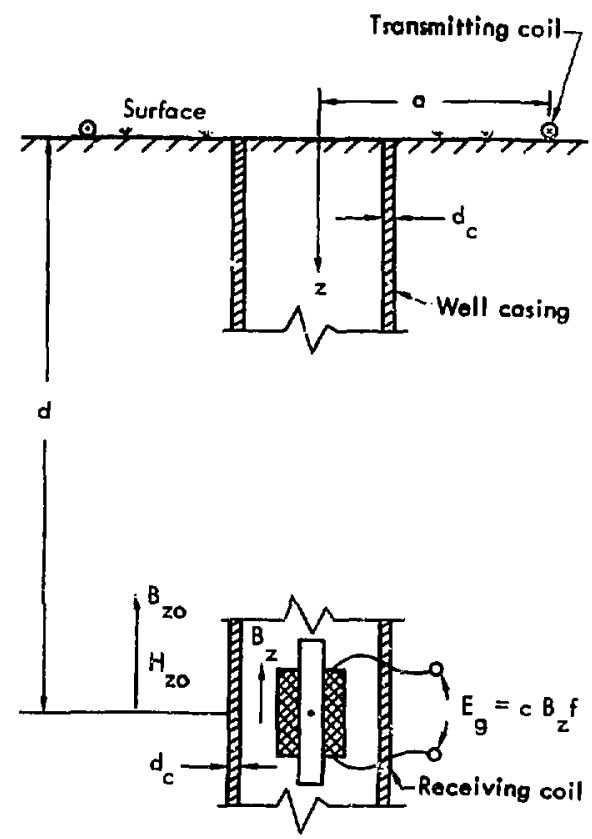

Fig. 1. Magnetic Induction system. The parameters are as follows: $u=u_{0}=4 \pi \times 10^{-7} \mathrm{H} / \mathrm{m}$, $\tau_{r}=10^{-2} \mathrm{mho} / \mathrm{m}, \mathrm{d}=11,000 \mathrm{ft}$ $=3350 \mathrm{~m}, a=500 \mathrm{~m}$.

a multi-turn receiving coil is located $11,000 \mathrm{ft}$ downhole as shown. The two coils are nominally concentric. The surface transmitting coil is driven with an rms current, $I$, and the resulting induced rms voltage appearing at the terminals of the receiving coil is $E_{\mathrm{g}}$.

The $E M$ radiated fields from such a horizontal loop are a maximum in the plane of the coil and zero along its axis. But the low frequency (magnetostatic) magnetic field is a maximum along the axis. This is the field which induces a voltage in the downhole coil.

Expressions for the fields produced by a loop over a conducting half-space appear in the geophysical prospecting literature. ${ }^{2-5}$ However these expressicns must be modified to account for the presence of the highly conductive well casing which surrounds the receiving coil. 


\section{Electrical Parameters of Half-Space, Wave Number, and Skin Depth}

The conductivity, $\sigma_{r}$, of the half-space is taken to be $10^{-2} \mathrm{mhos} / \mathrm{m}$ (resistivity, $p=100 \mathrm{ohm}-\mathrm{m}$ ) which is relatively high for rocks ( $\%$ f. Keller and Frischknecht ${ }^{1}$ ). Assuming the absence of any magnetic minerals, the magnetic permeability, $\mu$, of the half-space is essertially that of free space: $\mu=\mu_{0}$. The dielectric permittivity, $\epsilon$, of rocks varies over several orders of magnitude depending on the frequency and on the presence or absence of pore water. However, at the low frequencies

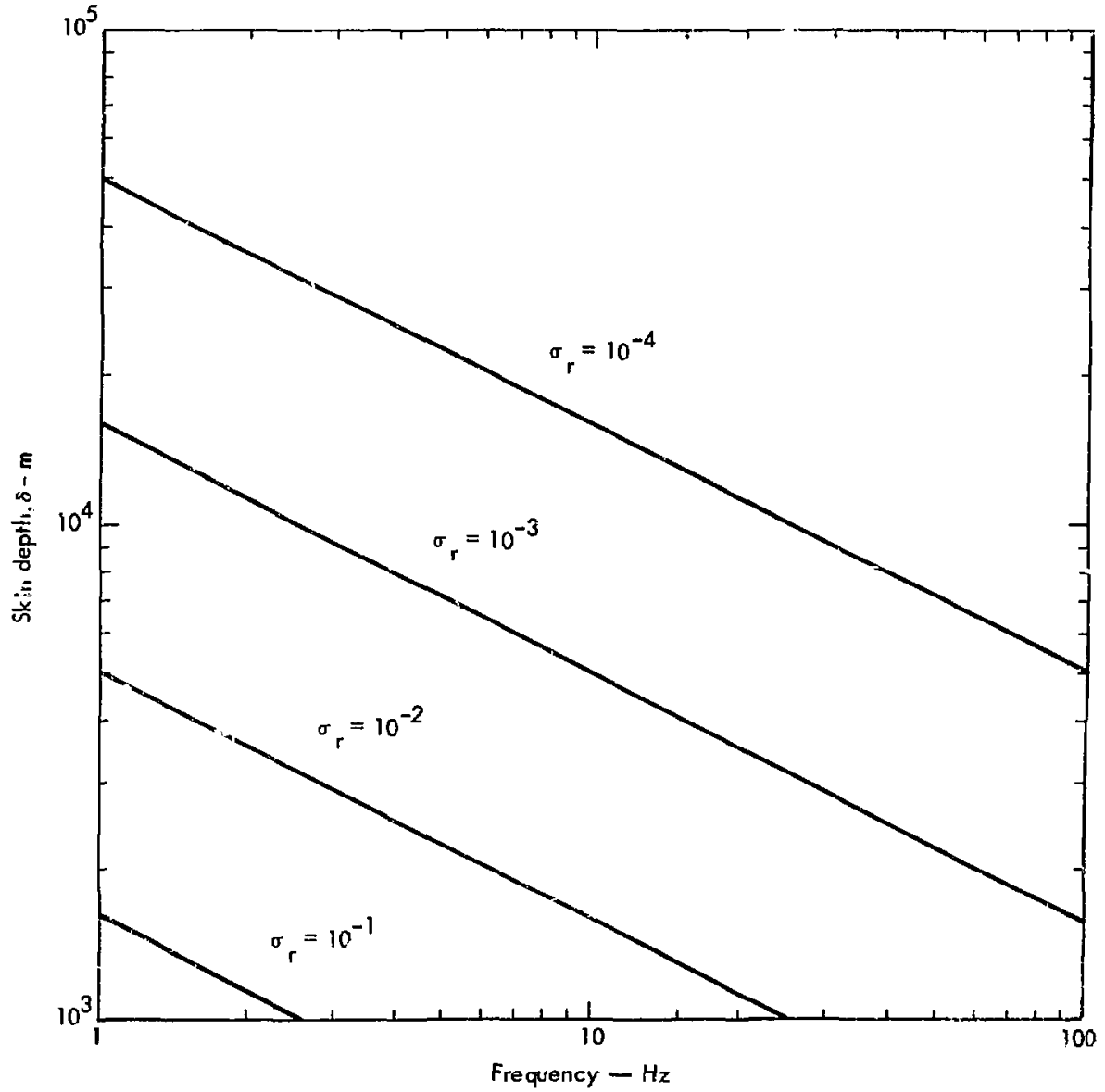

Fig. 2. Electrical skin depth in rocks for several rock conductivities $\left(\sigma_{r}\right)$ anơ taking $\mathrm{K}_{\mathrm{m}}$ as unity. 


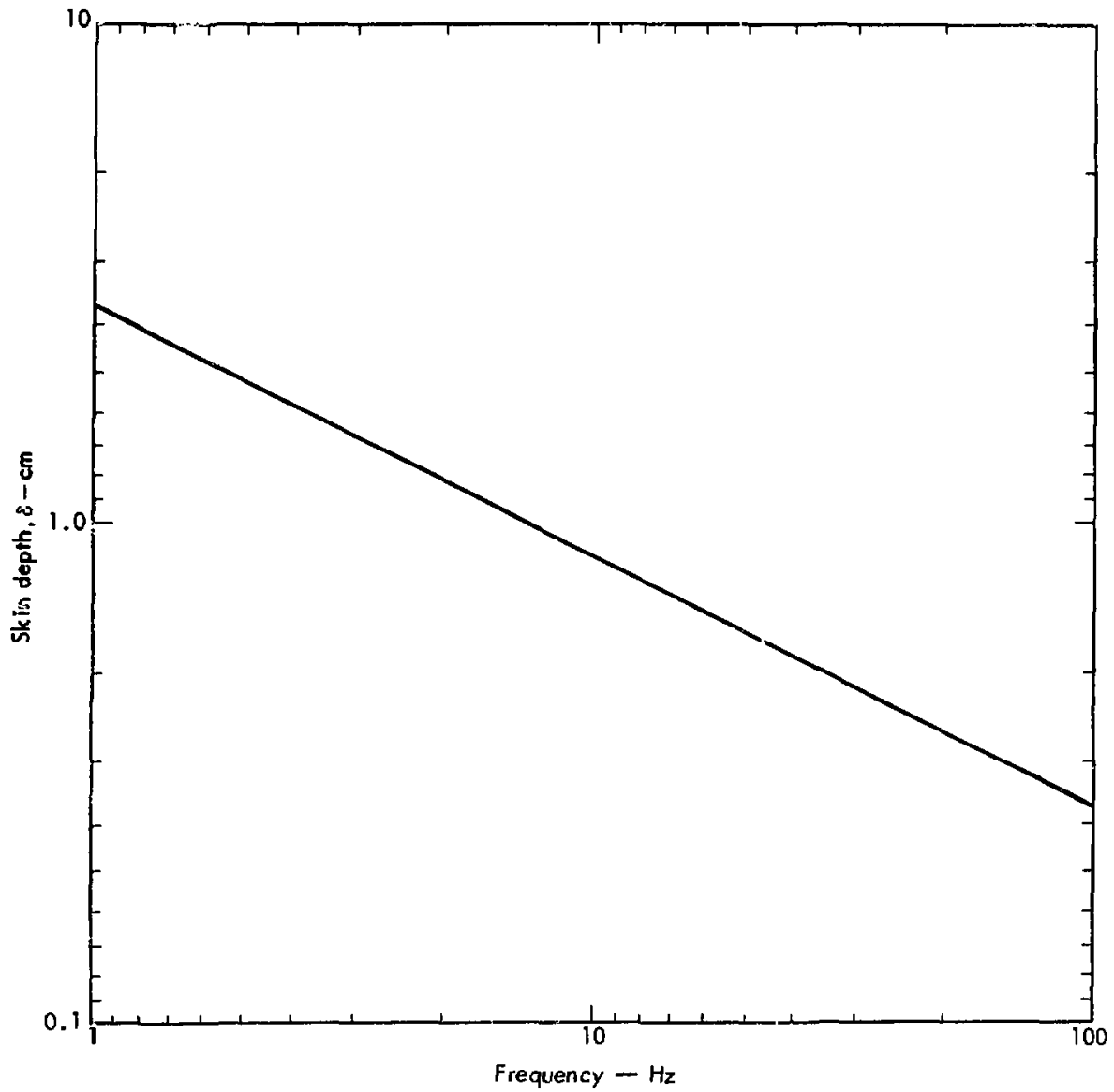

Fig. 3. Electrical skin depth ( $\delta$ ) as measured in P-110 steel well-casing.

involved in magnetic induction, the dis-

$$
\mathbf{k}=\left[\omega^{2} \mu \epsilon+i \omega \mu \sigma \mathbf{r}\right]^{1 / 2}
$$

placement currents are completely negligible (it will be shown) with respect to the conduction currents, so that the permittivity does not enter into the problem.

The basic aspects of plane wave propagation in good conductors are summarized in the Appendix. For conductors, the complex wave number $\mathrm{k}$ is given by:

The first ter'm is due to the displacement current and the second is due to conduction current. For frequencies below $15 \mathrm{~Hz}$, the conduction term is some 15 orders of magnitude greater than the displacement term, thus:

$$
k=\left[i \omega \mu \sigma_{\mathbf{r}}\right]^{1 / 2} .
$$


Separating $k$ into its real and imaginary parts, there results:

$$
k=\frac{1}{\delta}(1+i)
$$

where $\delta$ is the skin depth in meters given by:

$$
\delta=\left[\frac{2}{\omega \mu \sigma_{\mathrm{r}}}\right]^{1 / 2}=\frac{504}{\left|\sigma_{\mathrm{r}} \mathrm{K}_{\mathrm{m}} \mathrm{f}\right|^{1 / 2}}
$$

$\mathrm{K}_{\mathrm{m}}$ is the relative magnetic permeability defined by the relation:

$$
\mathrm{K}_{\mathrm{m}}=\frac{\mu}{\mu_{0}}
$$

Figure 2 gives skin depths in rocks from 1 to $100 \mathrm{~Hz}$ for a range of rock conductivities. For example, at $4 \mathrm{~Hz}$ and $a_{r}=10^{-2} \mathrm{mhos} / \mathrm{m}, \delta_{r}=2.5 \mathrm{~K}_{\mathrm{m}}$. Of course, for the same frequency, the skin depth in the well casing material is very much smaller because the term $\sigma \mathrm{K}_{\mathrm{m}}$ is so much larger for steel than rocks. Figure 3 gives skin depth in $\mathrm{cm}$ from 1 to $109 \mathrm{~Hz}$ for P-110 steel well casing material. At $5 \mathrm{~Hz} \delta=1.7 \mathrm{~cm}=0.67 \mathrm{in}$.

\section{Magnetic Field}

\section{FIELD EXTERIOR TO CASING}

The magnetic field exterior to the well casing due to a loop lying on the surface is denoted by the symbol $\mathrm{B}_{z 0}$ in Fig. 1 . Since at frequencies of several $\mathrm{Hz}$ the losses in the casing are severe, the external field may be calculated as if the casing were not there. In other words, the casing is not effective in the bringing additional magnetic field lines to any appreciable depth. This point was verified by means of a number of laboratory experiments using scaled models.

An analytical expression for the fields due to a loop source of current over a layered half space is given by Ryu, et al. ${ }^{4}$ For the vertical field concentric with the loop:

$$
\begin{gathered}
H_{z 0}(0, z, \omega)=\operatorname{aI}(\omega) f_{0}^{\infty} \\
\left(\frac{e^{-u_{0} z}}{u_{0}} \cdot \frac{z^{1}}{z_{0}+z^{1}} \lambda\right.
\end{gathered}
$$

$$
\left.-\frac{e^{-\lambda a}}{2}\right) J_{1}(\lambda a) \lambda d \lambda+\frac{a^{2} I(\omega)}{2\left(a^{2}+z^{2}\right)^{3 / 2}} .
$$

where in general the input impedance to the $i^{\text {th }}$ layer is given by:

$$
z^{i}=z_{i} \frac{z^{i+1}+z_{i} \tanh \left(u_{i} h_{i}\right)}{z_{i}+z^{i+1} \tanh \left(u_{i} h_{i}\right)}
$$

and

$$
\begin{aligned}
& z_{i}=-\frac{i \omega \mu_{i}}{\mu_{i}} \\
& \mu_{i}=\left(\lambda^{2}-k_{i}^{2}\right)^{1 / 2} .
\end{aligned}
$$

As the frequency becomes lower, the last term, which is the magnetostatic term, predominates:

$\mathrm{H}_{\mathrm{zO} \text { magnetostatic }}=\frac{\mathrm{a}^{2} I(w)}{2\left(\mathrm{a}^{2}+d^{2}\right)^{3 / 2}}$. 
The formal requirement for the magnetostatic approximation to hold is that:

$$
|k z|<1
$$

For the range of frequencies and rock conductivities considered here, $|\mathrm{kz}|<3$. For this reason the magnetostatic approximation will be used with the magnitude of the field reduced by the factor $\exp (-d / \delta)$. The resulting approximation " for the exterior field is then given by:

$$
\left|B_{z o}\right|=\mu_{o} \epsilon^{-z / \delta} \cdot \frac{a^{2} I}{2\left(a^{2}+d^{2}\right)^{3 / 2}} .
$$

\section{FIELD INTERIOR TO CASING}

As a first approximation, the ficld, $B_{z}$, inside the well casing may be related to the exterior field by the relation:

$$
\left|B_{z}\right|=\left|B_{z o}\right|^{-\frac{d_{c}}{\delta_{c}}}
$$

where

$$
\begin{aligned}
d_{c}= & \text { wall thickness of well casing in } \\
& \text { meters, and } \\
\delta_{c}= & \text { skin depth in casing material at } \\
& \text { frequency } \mathrm{f} .
\end{aligned}
$$

\footnotetext{
It should be realized that there is no radiated field along the axis - also that the skin depth term implies plane wave excitation which is not the case in the near field of the coil. The validity of this approximation, however, was verified experimentally (as shown later).
}

Again, this expression is approximate for the previously stated reasons. However, the approximation was tested experimentally using vertical stael pipes and an overhead loop. The frequencies, 122 and $140 \mathrm{~Hz}$, were chosen so that product $\left|k d_{c}\right|$ in the pipe matched the product $\left|\mathbf{k} d_{c}\right|$ expected with typical $1 / 2 "$ thick well casing. It was found, using several thicknesses of pipe, that the formula predicted the internal fields with only a $10 \%$ error.

An idea of the order of magnitilde of the interior field to be expected in an actual deep well is obtained by taking the following set of parameters:

$$
\begin{aligned}
\mathrm{a} & =500 \mathrm{~m} \\
\mathrm{~d} & =11,000 \mathrm{ft}=3.35 \times 10^{3} \mathrm{~m} \\
\mathrm{~d}_{\mathrm{c}} & =0.5 \mathrm{in} .=1.37 \times 10^{-2} \mathrm{~m} \\
\mathrm{I} & =20 \mathrm{~A}(\mathrm{rms}) \\
\mathrm{f} & =4 \mathrm{~Hz} \\
\sigma_{\mathrm{r}} & =10^{-2} \mathrm{mhos} / \mathrm{m}, \sigma_{c} \mathrm{~K}_{\mathrm{mc}}=2 \times 10^{8} .
\end{aligned}
$$

Then $\left|B_{z}\right| \sim 10^{-11} \frac{\text { webers }}{m^{2}}\left(=10^{-7}\right.$ gauss $=10^{-2}$ gamma). While it is possible to detect a 0.01 -gamma signal with a modern optically pumped magnetometer or a Josephson junction magnetometer, it is not practical because of the effort required to harden the magnetometer against the seismic shock ( 2000 g) accompanying the initial nuclear detonation. For this reason a many-turn receiving coil is employed downhole. 


\section{Nuise Considerations}

The noise appearing at the terminals of the coil will be of two types: Johnson noise and geomagnetic nuise. Assume that the coil has a capacitor across it limiting the bandwidth to $2 \mathrm{~Hz}$. Then the Johnson noise at $200^{\circ} \mathrm{C}$ is given by

$$
\begin{aligned}
E_{m s}=[4 \mathrm{kTR} \Delta]^{1 / 2}= & {[4 \times 1.38} \\
& \times 10^{-23} \times 473 \times 60 \\
& \left.\times 10^{3} \times 2\right]^{1 / 2} \cong 50 \mathrm{nV} .
\end{aligned}
$$

The geomagnetic noise in the coil is due to sferics and micropulsations in the low ELF region. At the surface this noise is variable but is about $10^{-3} \gamma$ $=10^{-8}$ gauss $=10^{-12}$ webers $/ \mathrm{m}^{2}$ total field. Because the velocity of propagation in the conducting ground is so much less than that in free space, most of the magnetic field propagating downward will be horizontally polarized, with very little vertical component remaining. Assurne the vertical geomagnetic field at $11,000 \mathrm{ft}$ is one-tenth its surface value. Then at the coil:

$\mathrm{B}_{\mathrm{z} \text { geomagnetic noise }} \approx 10^{-13}$ webers $/ \mathrm{m}^{2}$.

This is to be compared with the field due to the transmitting loop which was previously found to be $\sim 10^{-11}$ webers $/ \mathrm{m}^{2}$. So it appears that both the Johnson noise and the geomagnetic noise will be at least several orders of magnitude below the transmitted signal level.

\section{Field Experiment}

In order to check the theory and feasibility of communication through a cased hole, a field experiment was conducted on site at Lawrence Livermore Laboratory in an abandoned well. This well is $750 \mathrm{ft}$ deep with water beginning at $150 \mathrm{ft}$. The casing material appeared to be $3 / 16$-in. iron formed into a 10-in. diameter cylinder.

The transmitter coil is $20 \mathrm{ft}$ in diameter and consists of 15 turns of No. 10 wire. It was driven at $20 \mathrm{~Hz}$ with $0.7 \mathrm{~A}$ from a power amplifier. The resulting magnetic moment was $20 \mathrm{~A}-\mathrm{m}^{2}$.

A downhole receiving coil was constructed by stacking a dozen choke cores on a steel rod and connecting them in series aiding. The resulting coil had the following electrical parameters;

$$
\begin{aligned}
& R=60 \mathrm{k} \Omega \\
& L=2400 \mathrm{H} \\
& C=4 \times 10^{4} \frac{\text { volts }}{\text { weber } / \mathrm{m}^{2}-\mathrm{Hz}} .
\end{aligned}
$$

The receiving coil was calibrated on the surface using the known field generated by the transmitting coil:

$$
B_{z \text { surface }}=\mu_{0} \frac{\mathbb{N}}{2 a} \text {. }
$$

It was then lowered to $20 \mathrm{ft}$ where a frequency response test was run. See Fig. 5. Data was then taken every $10 \mathrm{ft}$ to $100 \mathrm{ft}$ and every $100 \mathrm{ft}$ to $300 \mathrm{ft}$, at which point 


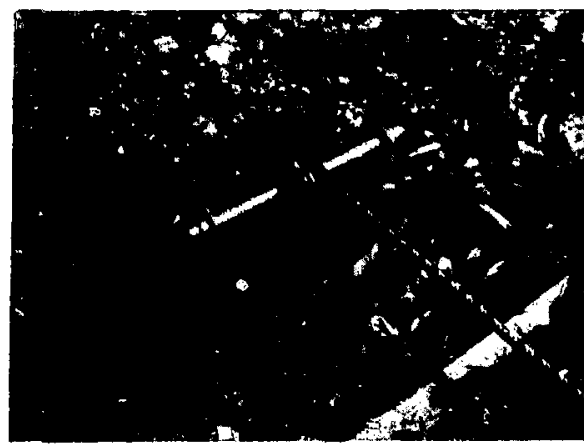

Fig. 5. Head of test hole at Livermore.

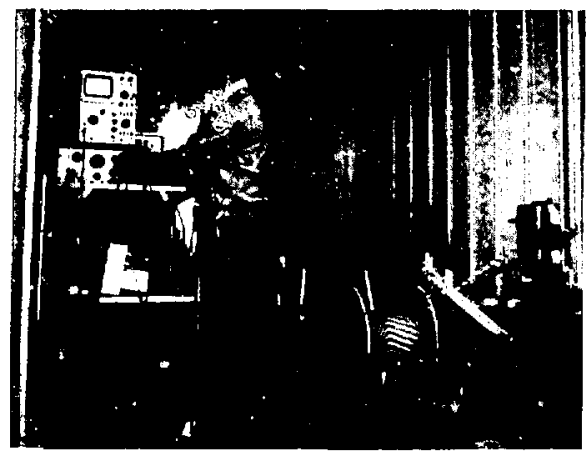

Fig. 6. Instrumentation shed.

water began to leak into the coil, forcing termination of the test.

The instrumentation consisted of a PAR - HR/8 phase lock amplifier driving a Mackintosh $M-75$ Hi $F i$ amplifier. The voltage $\mathrm{E}_{\mathrm{g}}$ developed by the coil was brought up a coaxial line and recorcied by the HR/8. See Fig. 6. An additional coaxial line terminated in a $66-\mathrm{k} \Omega$ resistor was also brought up to measure the amount of signal induced in the signal coaxial line by the surface transmitting coil. A block diagram of the entire system is shown in Fig. 7.

The experimental resilts of the depth tests at $20 \mathrm{~Hz}$ are given in Fig. 8. The theoretical values were calculated using Eq. (15) with the measured value of $\mathrm{C}$ and an assumed $\sigma_{\mathrm{F}}=10^{-2} \mathrm{mho} / \mathrm{m}$ for the rocks and $\sigma_{c} \stackrel{\mathrm{K}}{\mathrm{mc}}_{\mathrm{F}}=2 \times 10^{9}$ for the iron well casing. The good fit of the experimental and theoretical data up to the point where leaking developed is due mainly to the fact that the external field is falling off roughly as $\mathrm{d}^{-3}$. A better check on the frequency-dependent part of Eq. (15) is obtained by the frequency response test which was run at a fixed coil depth of $20 \mathrm{ft}$.

The resulting data is presented in Fig. 9. It was convenient to normalize the ordinate values by dividing $B_{z}$ surface. As is seen, the data fit reasonably well to about $40 \mathrm{~Hz}$. The fit at $50 \mathrm{~Hz}$ cu'lld be improved by changing parameters $\sigma_{\mathbf{r}}$ and $\sigma_{c} K_{m c}$ which are responsible for the fall off at higher frequencies. 


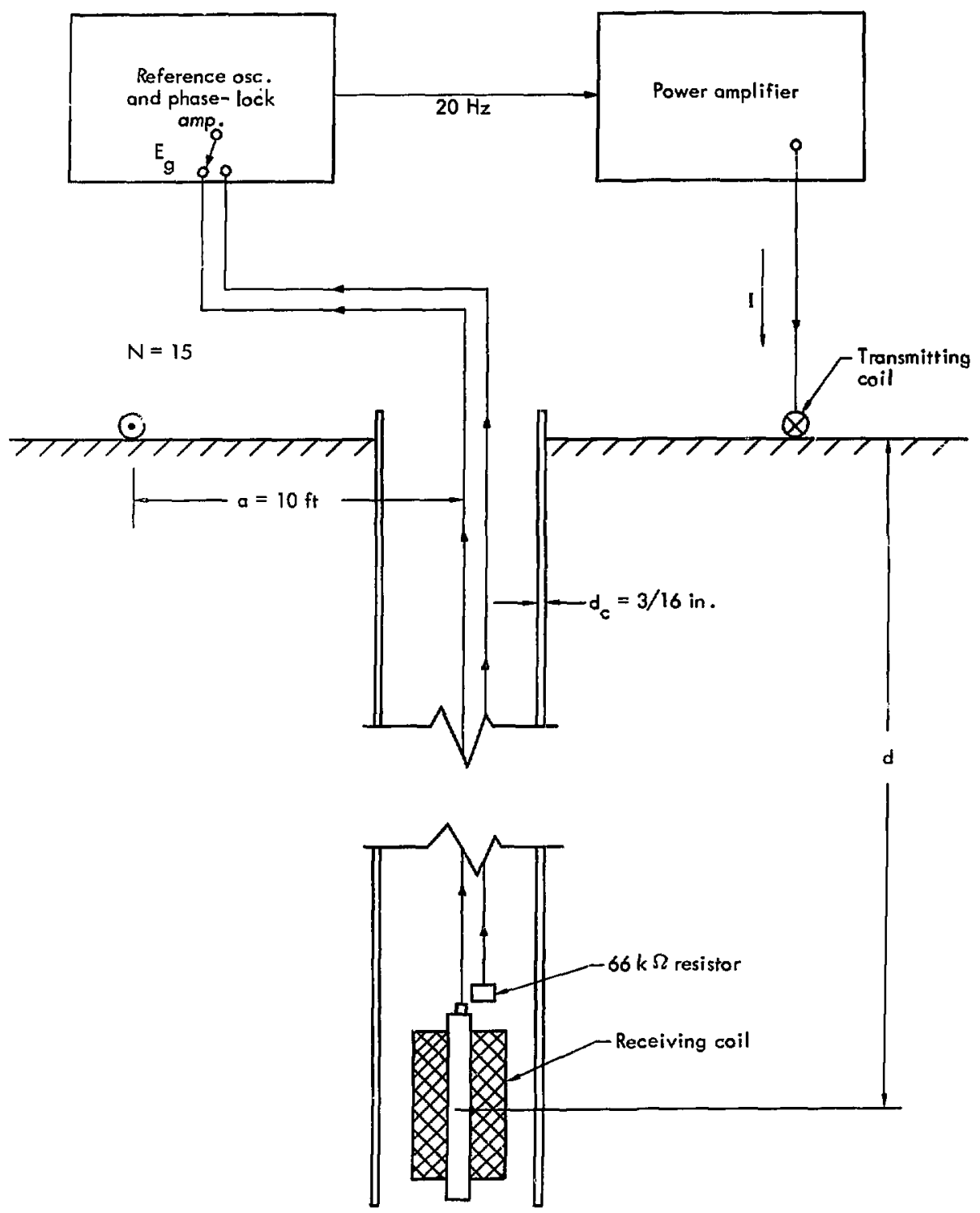

Fig. 7. Block diagram of test well instrumentation. 


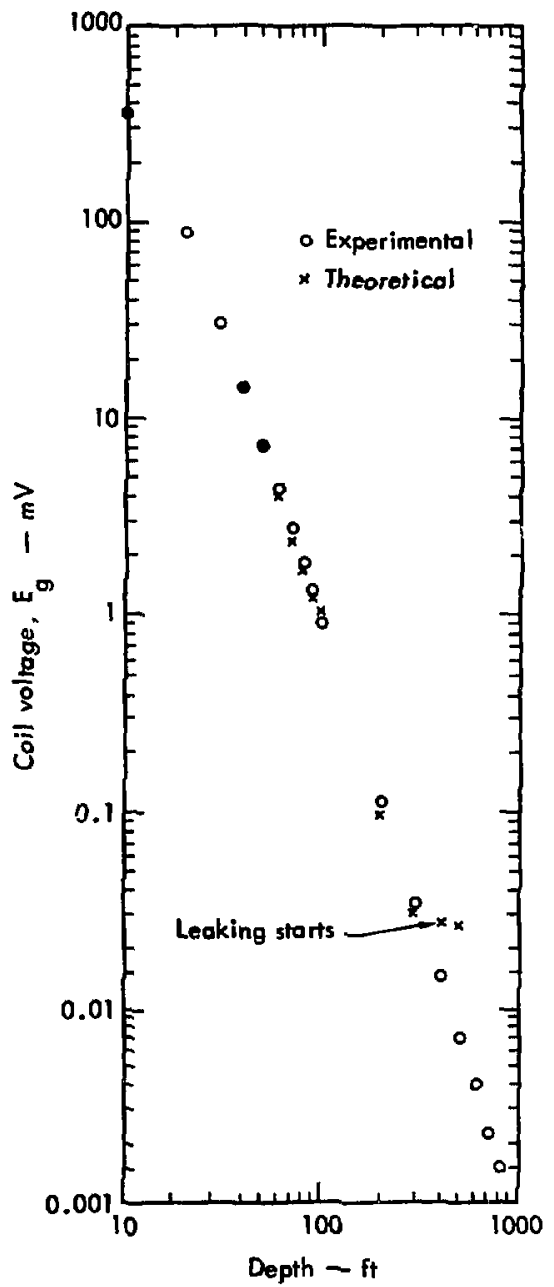

Fig. 8. Coil voltage $\left(E_{p}\right)$ versus downhole depth using $20 \mathrm{~Hz}$ transmission frequency. (Livermore test hole, 3/16-in. casing.) 


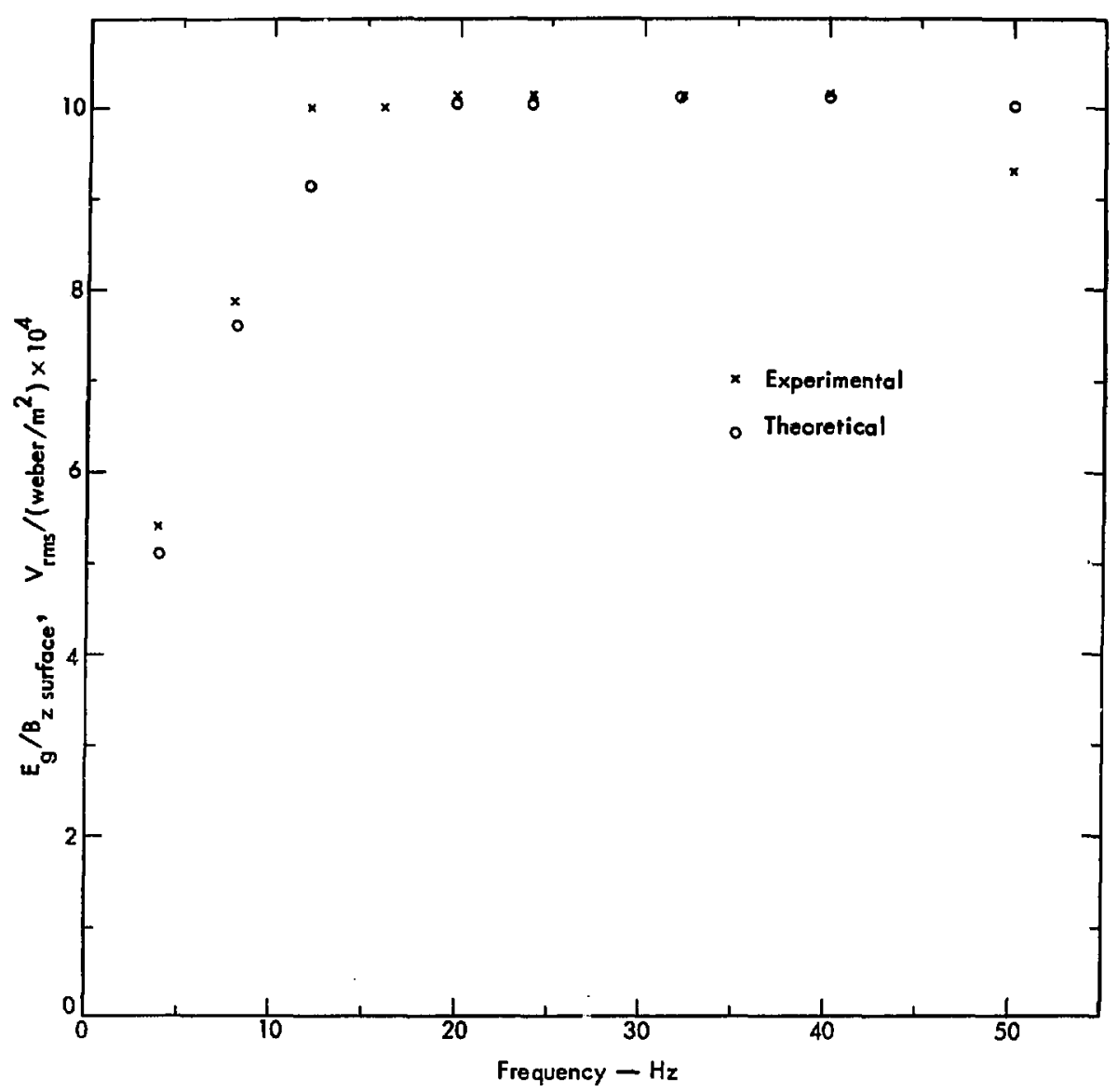

Fig. 9. Volts/(weber $/ \mathrm{m}^{2}$ ) versus transmitting frequency at downhole depth of $20 \mathrm{ft}$ in Livermore test hole. 


\section{Summary and Conclusions}

It has been shown theoretically and experimentally that it is practical to communicate with a downhole coil in a cased hole using the induction field produced by a large surface loop of wire. The $1 / d^{3}$ geometrical attenuation and the attenuation through the rocks and the steel well casing is discussed and measured. A field experiment on site is described. The results of the experiment confirm the approximate theory and tend to verify the practicality of the method.

Further field tests on the complete system have been run by Sandia Laboratories using a deep cased hole in a
Wyoming gasfield (Wagon Wheel). The hole is $11,000 \mathrm{ft}$ deep and is cased with $1 / 2-$ in. thick steel at that depth. A $1-\mathrm{km}$ diameter surface loop was driven with $5 \mathrm{~A}$ $(\sim 100 \mathrm{~W})$ at $5 \mathrm{~Hz}$. The resulting signals developed in the downhole coil were in the $0.1 \mu \mathrm{V}$ range at the $10,000-\mathrm{ft}$ level; and in general the data confirmed the theory.

It is felt that the work reported here completes the feasibility phase of the study. Remaining to be accomplished are the engineering design, construction, and field test of a complete system including the downhole electronics and packaging.

\section{Acknowledgments}

I am indebted to my colleagues M. Jaroska, J. Carson, O. Krause, and $G$. Longerbeam for their encouragement in this project and their assistance in overcoming the handicap of working in isolation without access to a converient library. I also want to thank J. Campbell for constructing the downhole coil and assisting in the field experiment. 


\section{Appendix:}

\section{Plane Wave Propagation in Good Conductors}

For plane wave propagation in a conductive, charge- and source-free homogeneous medium, both $E$ and $H$ satisfy wave equations of the form:

$\nabla^{2} E-\mu \epsilon \frac{\partial^{2} E}{\partial t^{2}}-\mu \sigma \frac{\partial E}{\partial t}=0$

$\nabla^{2} \mathrm{H}-\mu \epsilon \frac{\partial^{2} \mathrm{H}}{\partial \mathrm{t}^{2}}-\mu \sigma \frac{\partial \mathrm{H}}{\partial \mathrm{t}}=0$.

Assume propagation in the $\mathrm{z}$-direction and solutions of the form:

$$
\left\{\begin{array}{l}
E \\
H
\end{array}\right\}=\operatorname{Re}\left\{\begin{array}{l}
E \\
H
\end{array}\right\} \epsilon^{i \omega t-k z^{\prime}}
$$

where $k$ is the complex propagation constant given by:

$$
\begin{aligned}
k(\omega) & =\left[i \omega \mu \sigma+\omega^{2} \mu \epsilon\right]^{1 / 2} \\
& =\alpha(\omega)+i \beta(\omega)
\end{aligned}
$$

$\alpha(\omega)$ is the attenuation in nepers/m and $\beta(\omega)$ is the phase function in radians $/ \mathrm{m}$. In general,

$\alpha(\omega)=\omega\left[\frac{\mu \epsilon}{2}\left(\sqrt{1+\frac{\sigma^{2}}{\epsilon^{2} \omega^{2}}}+1\right)\right]^{1 / 2}$.

and $\beta(\omega)=\omega\left[\frac{\mu \epsilon}{2}\left(\sqrt{1+\frac{\sigma^{2}}{\epsilon^{2} \omega^{2}}}-1\right)\right]^{1 / 2}$.

The phase velocity $v_{p}$ is given by:

$$
v_{p}=\frac{\omega}{B(\omega)} \text {. }
$$

For good conductors the conduction current density $\sigma \mathrm{E}$ greatly exceeds the displacement current density $\partial D / \partial t$, or:

$$
\frac{\sigma}{W E} \gg 1 \text {. }
$$

Equations $(A-6)$ and $(A-7)$ then simplify to:

$$
\alpha(\omega)=\beta(\omega)=\sqrt{\frac{\omega \mu \sigma}{2}}
$$

80:

$$
k(\omega)=\frac{1+i}{\delta}
$$

where $\delta$ is defined as the skin depth:

$$
\delta=\sqrt{\frac{2}{\omega \mu \sigma}}=\frac{504}{\left[\sigma \mathrm{K}_{\mathrm{m}}\right]^{1 / 2}} .
$$

Equation $(A-3)$ then becomes:

$\left\{\begin{array}{l}E \\ \mathrm{H}\end{array}\right\}=\operatorname{RE}\left\{\begin{array}{l}E \\ \mathrm{H}\end{array}\right\} \epsilon^{i \omega t-\frac{(1+i)}{\delta}}$.

Then the decay with propagation in the $z$-direction is governed by the factor: $\exp (-2 / \delta)$. 


\section{References}

1. G. V. Keller and F.C. Frischknecht, Electrical Methods in Gaophysical Frospecting (Pergamon Press, New York, NY, 1966).

2. L. Vanyan, Electromagnetic Depth Soundings (Special Research Report, Consultants Bureau, New York, NY, 1967).

3. Mining Geophysics, vol. II (Society of Exploration Geophysicists, Tulsa, CK, 1967).

4. J. Ryu, H.F. Morrison, and S. H. Ward, "Electromagnetic Fields s:bout a Loop Source of Current," Geophysics 35, 862-896 (1970).

5. J. H. Moran and K.S. Kunz, "Basic Theory of Lnduction Logging and Application to Study of Two-Coil Sondes," Geophysics 27, 829-858 (1962).

6. J. A. Stratton, Electromagnetic Theory (McGraw-Hill, New York, NY, 1941).

7. Reference Data for Radio Engineers (International Telephone and Telegraph Corp., New York, NY, 1949). 